Communication

\title{
A Composite Joint Based on Two Kinds of Connection Mechanisms for TA2/T2 Bimetallic Sheets by Laser-TIG Hybrid Weldings
}

\author{
Yan Zhang ${ }^{1}$, , Yidi Gao ${ }^{1}$, Jianping Zhou ${ }^{1}$, Daqian $\mathrm{Sun}^{2}$, Hongmei $\mathrm{Li}^{2}$ \\ ${ }^{1}$ State Key Laboratory for Manufacturing Systems Engineering, School of Mechanical Engineering, Xinjiang University, Wulumuqi, China \\ ${ }^{2}$ Key Laboratory of Automobile Materials, School of Materials Science and Engineering, Jilin University, Changchun, China \\ Email address: \\ yanzhang4967@163.com (Yan Zhang) \\ ${ }^{*}$ Corresponding author
}

\section{To cite this article:}

Yan Zhang, Yidi Gao, Jianping Zhou, Daqian Sun, Hongmei Li. A Composite Joint Based on Two Kinds of Connection Mechanisms for TA2/T2 Bimetallic Sheets by Laser-TIG Hybrid Weldings. Advances in Materials. Vol. 9, No. 3, 2020, pp. 55-58.

doi: 10.11648/j.am.20200903.13

Received: September 1, 2020; Accepted: September 14, 2020; Published: October 20, 2020

\begin{abstract}
The possibility of two pass welding for TA2/T2 bimetallic sheets joint with laser-TIG hybrid weldings was studied. Laser-gas tungsten arc welding (TIG) hybrid welding of TA2/T2 bimetallic sheets has been applied using BCuP-2 wire as filler metal. A new welding process for TA2/T2 butt joint was introduced on the basis of the controlling the formation of Ti-Cu intermetallics in the joint. One process was two pass welding involving creation of a joint with one laser weld and one TIG weld separated by remaining unmelted TA2/T2 interface. When laser beam on the TA2 side junction surface, T2 would not be completely melted in joint. When TIG welding in groove, the filler metal melted occurred at the TA2 and T2 interfaces. Through two pass welding, the the formation of $\mathrm{Ti}-\mathrm{Cu}$ intermetallics can be completely avoided during welding. In the paper, microstructure and mechanical characterization of Ti/Cu clad plates laser and arc welded joints were carried out. The unmelted part of TA2/T2 explosive interface acted as a diffusion barrier between $\mathrm{Ti}$ and $\mathrm{Cu}$. The unmelted TA2/T2 explosive interface was beneficial to relieve and accommodate the thermal stress. The joint fractured mainly at the brazed weld with the maximum tensile strength of $610 \mathrm{MPa}$.
\end{abstract}

Keywords: TA2/T2, Bimetallic Sheets, Welding, Microstructure, Filler Metal, Tensile Strength

\section{Introduction}

Titanium and its alloys have excellent comprehensive properties, namely high specific strength, high specific modulus, toughness, corrosion resistance and high damage resistance [1]. Copper and its alloys have excellent electrical conductivity, thermal conductivity and ductility, good cold and hot workability, high oxidation resistance and corrosion resistance [2]. However, compared to the performance of a single material, Ti-Cu 's multiple materials can take advantage of the performance and cost advantages of each material to select the best material for each structural component [3]. $\mathrm{Ti} / \mathrm{Cu}$ composite plates with good interface and uniform thickness distribution are used in many industries [4]. The effective jointing of $\mathrm{Ti} / \mathrm{Cu}$ dissimilar materials can not only meet the requirements of thermal conductivity, conductivity, corrosion resistance, wear resistance, but also meet the requirements of high strength but light weight. Therefore, it will have broad application prospects in aerospace, instrumentation, electronics, chemical and other fields. At present, the welding of titanium and copper is mainly concentrated on brazing and solid phase welding, such as friction welding, explosive welding and ultrasonic welding [5]. The previous research results show that the solid phase welding method shows certain advantages due to its excellent connection method and good welding quality. Explosive welding has the characteristics of large explosion pressure and large deformation heat, which can be used for welding dissimilar metals [11-13]. A good metal bonding can be achieved between dissimilar metals by controlling the explosion parameters and thermal diffusion. Kahraman and 
Gülenç bonded Ti6Al4V with industrial $\mathrm{Cu}$ by explosion welding, and the fracture occurred on the $\mathrm{Cu}$ plate [6]. The bond was metallurgical in nature and usually as strong or stronger than the weaker parent metal. Fendik conducted a comprehensive review of explosive welding and reported more than 260 similar and dissimilar metals and alloys [7]. Through explosive welding, many large composite plates with high surface area can be manufactured, which is difficult to achieve by other welding methods [14].

The purpose of this study is to connect $\mathrm{Ti} / \mathrm{Cu}$ explosive composite plates by fusion welding. However, due to the metallurgical incompatibility between $\mathrm{Ti}$ and $\mathrm{Cu}$, a variety of complex intermetallic compounds such as $\mathrm{Ti}_{2} \mathrm{Cu}, \mathrm{TiCu}, \mathrm{Ti}_{3} \mathrm{Cu}_{4}$ can be formed, resulting in high brittleness of the joint [8]. In addition, with significant differences in melting points, coefficients of expansion, and thermal conductivity, welded joints can generate large residual stresses, resulting in poor mechanical properties of the joints. Cao et al. [9] successfully jointed industrial pure TA2 and pure $\mathrm{T} 2 \mathrm{Cu}$ with $\mathrm{ERCuNiAl}$ copper wire by $\mathrm{CMT}$ technology, and $\mathrm{Ti}_{2} \mathrm{Cu}$, TiCu and $\mathrm{AlCu}_{2} \mathrm{Ti}$ three-layer IMCs can be formed on the titanium-weld interface. Zhao et al. [6] reported the microstructure and properties of $\mathrm{Cu} / \mathrm{Ti}$ laser welded joints. The results showed that the formation of IMCs at the titanium weld metal interface has a significant effect on the joint properties, and quasi-cleavage fracture occurred at the IMCs. In summary, there is a problem of brittle IMCs, leading to failure of joints in the dissimilar metals welding of Ti-6Al-4V and $\mathrm{Cu}$ alloy. Current research shows that the problem of Ti-Cu intermetallic compounds is difficult to solve, and further research on the effective connection mechanism between $\mathrm{Ti} / \mathrm{Cu}$ composite plates is needed. As a high-energy beam welding process, $\mathrm{Xu}$ et al. [10] confirmed that laser welding has the advantages of high energy density, fast heating/cooling speed, and high controllability. Due to these advantages of the laser, the position where the laser is incident can be precisely controlled to adjust the penetration of the Ti side in the welding of the $\mathrm{Ti} / \mathrm{Cu}$ composite plate, which will effectively increase the strength of the joint. Gas tungsten arc welding (TIG) is suitable for joining thin sections due to its limited heat input.

Based on this study, we proposed a novel method called laser beam and TIG superposition welding, and the main purpose was to avoid the mixing of $\mathrm{Ti}$ and $\mathrm{Cu}$ to prevent the appearance of Ti-Cu intermetallics in the joint. The aim of this study was to bond $\mathrm{Ti} / \mathrm{Cu}$ composite plates by laser and arc welding. The welding process was set to ensure that the sides of the TA2 and $\mathrm{T} 2$ were partially melted. The molten TA2 formed a weld zone by laser welding. Subsequently, the molten filler metal formed a weld zone on the T2 side by TIG welding. In this way, a hybrid joint was obtained and the formation of a Ti-Cu intermetallics could be completely avoided during welding. So far, this kind of joint has been rarely reported.

\section{Experimental}

The material used for this study was an explosively welded TA2/T2 bimetallic sheet. The bimetallic sheet were machined to a size of $80 \mathrm{~mm} \times 40 \mathrm{~mm} \times 5 \mathrm{~mm}$ for butt welding experiments, and including a $2 \mathrm{~mm}$ thick flyer layer (TA2 side) and a $3 \mathrm{~mm}$ thick parent layer (T2 side). Figure 1 shows the groove dimensions of the TA2/T2 bimetallic sheet. The double pass welding process is shown in Figure 2. In the first welding pass, the flake layers (TA2 side) were joined together by a single laser welding (Figure 2a and Figure 2b). In order to avoid melting of T2 side and ensure that TA2/T2 explosive interface was not melted, the laser beam was focused on the TA2 side and away from the interface between TA2 and T2 during welding. The welding parameters were: laser beam power of $500 \mathrm{~W}$, defocusing distance of $+5 \mathrm{~mm}$, welding speed of 650 $\mathrm{mm} / \mathrm{min}$. Argon gas with a parameter purity of $99.99 \%$ was used as a shielding gas, and the total flow rate at the top of the joint was $20 \mathrm{~L} / \mathrm{min}$. In the second welding pass, the parent layer (T2 side) was connected by a single TIG, and the filler material was $\mathrm{BCuP}-2$ wire $(97$ wt. $\% \mathrm{Cu})$. When the $\mathrm{BCuP}-2$ wire starts to melt, the groove at $\mathrm{T} 2$ side was completely immersed in the molten metal (Figure 2c and Figure 2d). In order to avoid melting of the TA2 side, it was ensured that the molten metal completely filled the trench. The welding parameters were: welding voltage of $220 \mathrm{~V}$, welding current of $40 \mathrm{~A}$, tungsten very diameter of $2.5 \mathrm{~mm}$. Argon gas with a purity of $99.999 \%$ was used as a shielding gas for the top, rear and back of the joint. The total flow of argon was approximately $15 \mathrm{~L} / \mathrm{min}$.

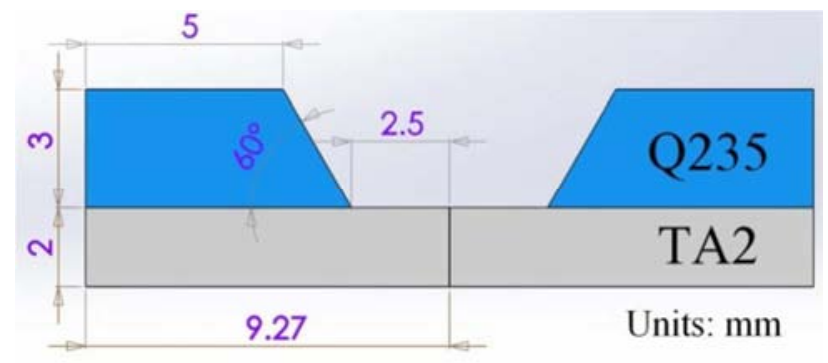

Figure 1. The groove dimensions of the TA2/T2 bimetallic sheet.
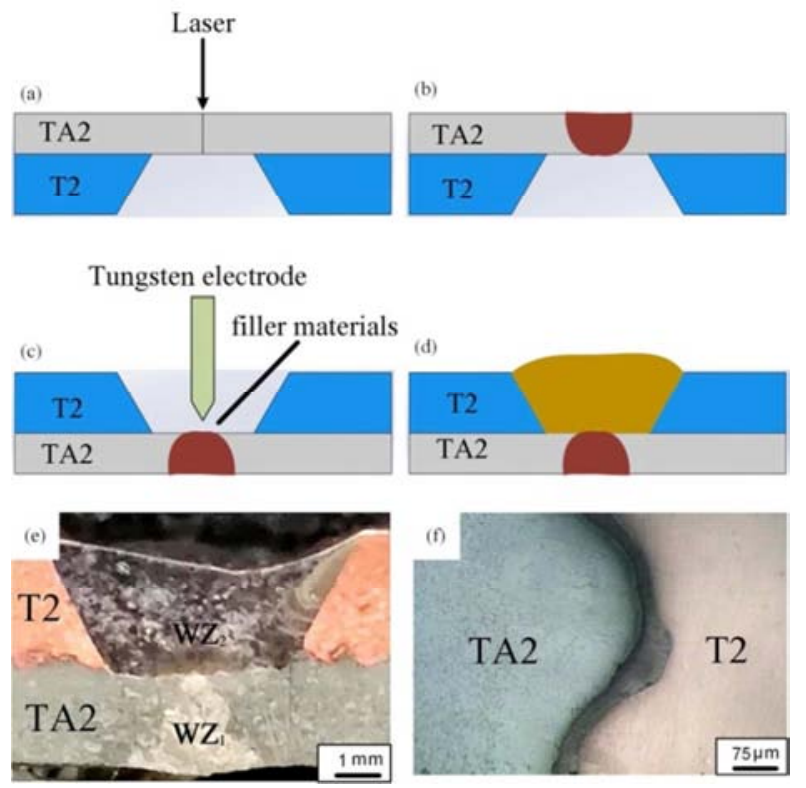

Figure 2. (a-b) schematic diagram of the first welding pass; (c-d) schematic diagram of the second welding pass; (e) optical image of the cross section of the joint; (f) optical image of the explosive interface of the TA2/T2. 


\section{Results and Discussion}

After welding, the macrostructure of the joint was examined. An OM image of the cross section of the joint is shown in Figure 2e. The joint could be divided into two parts: a first weld zone $\left(\mathrm{WZ}_{1}\right)$ formed on the TA2 side, a second weld zone $\left(\mathrm{WZ}_{2}\right)$ formed on the T2 side. As shown in Figure $2 \mathrm{f}$, the explosive interface of the TA2/T2 bimetallic sheet was wavy. Due to the T2 surface did not melt during the first welding pass, the $\mathrm{Ti}-\mathrm{Cu}$ intermetallic compounds were not formed in the $\mathrm{WZ}_{1}$. Meantime, the Ti-Cu intermetallic compounds were also not formed in the $\mathrm{WZ}_{2}$ due to the TA2 was not melted during the second welding pass. In this way, a joint with two welded regions separated by laser and TIG hybrid welding was obtained, and formation of a Ti-Cu intermetallics could be completely avoided during welding. Moreover, the two weld zones separated by laser and TIG hybrid welds helped to alleviate and accommodate the thermal stresses in the joints, which helped to improve the mechanical properties of the joint.
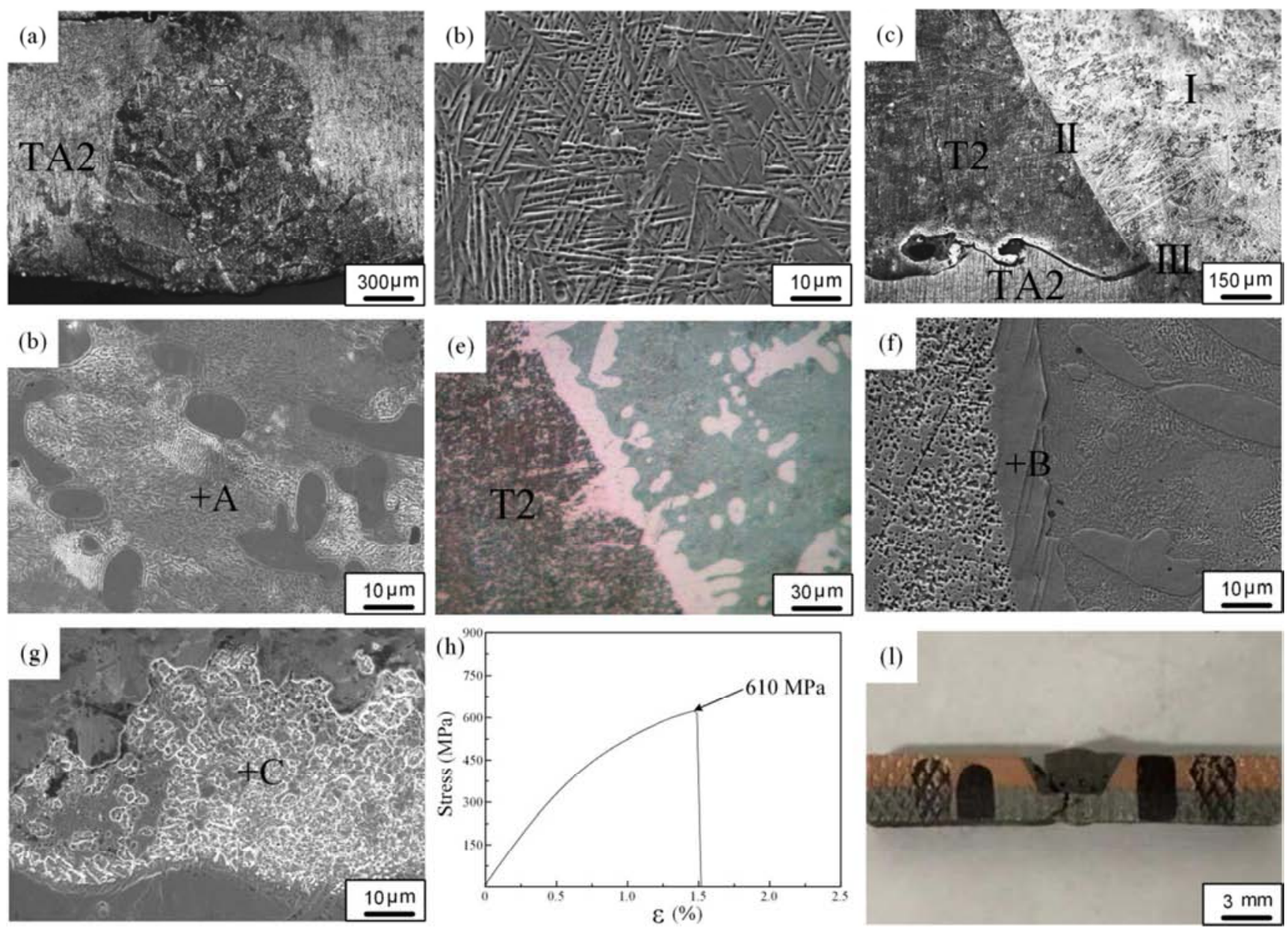

Figure 3. (a) optical image of the $W Z_{1}$; (b) SEM image of the $W Z_{1}$; (c) optical image of the $W Z_{2}$; (d) refer to the zone I in Figure $3 c$; (e) refer to the zone I in Figure 3c; (f) refer to the zone II in Figure 3c; (g) refer to the zone III in Figure 3c; (h) tensile test curve; (l) fracture location.

Table 1. The chemical composition of each phase (wt.\%).

\begin{tabular}{|c|c|c|c|c|c|c|c|c|}
\hline \multirow{2}{*}{ Region } & \multicolumn{7}{|c|}{ Composition \% } & \multirow{2}{*}{ Potential phases } \\
\hline & $\mathbf{T i}$ & $\mathrm{Fe}$ & $\mathbf{C u}$ & $\mathbf{V}$ & $\mathbf{N i}$ & $\mathrm{Cr}$ & Al & \\
\hline A & & & 97.2 & & & & & $\alpha-\mathrm{Cu}$ \\
\hline B & & & 98.4 & & & & & $\alpha-\mathrm{Cu}$ \\
\hline $\mathrm{C}$ & 88.3 & & 11.7 & & & & & $\beta-\mathrm{Ti}$ \\
\hline
\end{tabular}

The optical image of the $\mathrm{WZ}_{1}$ at TA2 side is shown in Figure $3 \mathrm{a}$, and no defects were observed in it. SEM image of the $\mathrm{WZ}_{1}$ is shown in Figure $3 \mathrm{~b}$. The $\mathrm{WZ}_{1}$ mainly consists of acicular $\alpha^{\prime}$ martensite. The optical image of the $\mathrm{WZ}_{2}$ at $\mathrm{T} 2$ side is shown in Figure 3c. It can be observed that, the $\mathrm{WZ}_{2}$ contained three zones marked as I, II and III sorted by their morphologies and colors. Figure 3d, Figure $3 e$, Figure $3 \mathrm{f}$ and Figure $3 \mathrm{~h}$ correspond to the three zones in Figure $3 \mathrm{c}$, respectively. The compositions of each zone (denoted by letter A-C in Figure 3) were studied using SEM-EDS. EDS analysis was applied to these zones to measure the compositions of the reaction products and the results are 
listed in Table 1. Based on the previous analysis, the microstructure of the $\mathrm{WZ}_{2}$ was mainly composed of molten BCuP-2 wire. It is seen in Figure $3 d$ that zone I presents characteristic of liquid phase microstructure. Therefore, the chemical composition of zone I was consistent with the BCuP-2 wire. The main microstructure of zone I was defined as $\alpha-\mathrm{Cu}$ phase. When the liquid phase is produced in groove at T2 side, the element diffusion occurs immediately between the base materials and liquid phase, and causes its component to deviate from the original component. Therefore, the liquid phase generation and the element diffusion occur simultaneously. Accompanied by the dissolution of solid phase into the liquid phase, atoms in the liquid phase would diffuse into T2 and TA2, which formed solid-phase reaction layer, and this reaction layer exists only in the smaller region of the interface. As shown in Figure $3 \mathrm{f}$ and $3 \mathrm{~g}$, zone II and zone III were reaction layers formed by element diffusion. The composition at position B of zone II was $\alpha-\mathrm{Cu}$ phase. The composition at position $\mathrm{C}$ of zone III was $\beta$-Ti solid solution. The maximum tensile strength of the joint was about $610 \mathrm{MPa}$ (Figure $3 \mathrm{~h}$ ). The joint fractured mainly in Ti alloy side during tensile tests (Figure 31 ).

\section{Conclusions}

With a laser beam was acted on the TA2 side butt interface, the unmelted TA2/T2 interface was selected as an barrier to avoid mixing of the TA2 and T2. For TA2 side of joint, microstructure of $\alpha^{\prime}$ martensite was obtained in $\mathrm{WZ}_{1}$. When single-pass TIG welding at T2 side, a great amount of liquid forms in groove at T2 side during welding. For T2 side of joint, main microstructure of $\alpha-\mathrm{Cu}$ was obtained in $\mathrm{WZ}_{2}$. The tensile resistance of the joint was determined by $\mathrm{WZ}_{1}$ and $\mathrm{WZ}_{2}$. The maximum tensile strength of joint was
$610 \mathrm{MPa}$.

\section{References}

[1] R. Lei, X. Wenlong, M. Chaol. Scripta Mater. 156 (2018) 4750 .

[2] X. Nan, Q. Song, Y. Bao, et al. Mater. Sci. Eng. A, 687 (2017) 73-81.

[3] S. Guo, Q. Zhou, Y. Peng. Mater. Des. 121 (2017) 51-60.

[4] Kahraman N, Gülenç B. J. Mater. Process. Technol., 2005, 169 (1): 67-71.

[5] J. G. Lee, G. H. Kim, M. K. Lee, et al. Intermetallics 18 (4) (2010) 529-535.

[6] Y. Zhao, W. Wang, K. Yan, et al. J. Mater. Process. Technol. 257 (2018) 244-249.

[7] Findik F. Mater. Design. 32 (2011) 1081-1093.

[8] R. K. Shiue, S. K. Wu, C. H. Chan. J. Alloy. Comp. 372 (1) (2004) 148-157.

[9] Cao, R, Feng, Z., Lin, Q., Chen, J. H. Mater. Des. 56 (2014) $165-173$.

[10] Xu, G., Wu, C., Ma, X., Wang, X. 26 (2013) 352-360.

[11] Yan Z, Yankun C, Jianping Z, et al. Welding in word. 2020, 64, 257-266.

[12] Yan Z, YanKun C, JianPing Z, et al. Journal of Materials Research and Technology. 2020, 9 (2), 1425-1433.

[13] Yan Z, Yuanbo B, Jianping Z, DaQian S, HongMei L. Journal of Materials Research and Technology. 2020, 9 (2), 1340-1343.

[14] Yan Z, Daqian S, Xiaoyan G, et al. Journal of Materials Engineering and Performance. 2019, 28 (10), 6092-6101. 